\title{
Mobbing Davranışlarının Öğrenci Tükenmişliğine Etkisi: Spor Bilimleri Fakültesi Lisans Öğrencileri Üzerinde Ampirik Bir İnceleme*
}

\author{
Süleyman Murat YILDIZ \\ Muğla Sıtkı Koçman Üniversitesi, Muğla.
}

Orijinal Makale

Gönderi Tarihi: 31.10.2019

Kabul Tarihi: 13.03.2020

DOI: $10.25307 /$ jssr.640401

Online Yayın Tarihi: 30.06.2020

$\ddot{\mathbf{O} z}$

Bu çalışmada mobbing davranışlarının üniversite öğrencilerinin tükenmişliği üzerine etkisi incelenmiştir. Veriler bir devlet üniversitesinin spor bilimleri fakültesindeki öğrencilerinden $(n=223)$ elde edilmiştir. Mobbing davranışlarını ölçmek için Einarsen ve diğerleri (2009) tarafından geliștirilen Negatif Davranıșlar Ölçeği'nin öğrencilere yönelik versiyonu kullanılmıştır. Öğrencilere yönelik versiyon bu çalışmada geliştirilmiş ve "Negatif Davranışlar Ölçeği-Öğrenci" olarak adlandırılmıştır. Ölçeğin geçerliliği için hem açımlayıcı hem de doğrulayıcı faktör analizi uygulanmıştır. Ayrıca, ölçeğin güvenirliği için Cronbach's alpha katsayısı hesaplanmıştır. Geçerlik ve güvenirlik analizleri yüksek değerler göstermiş ve sonuçta ölçeğin 12 maddeli ve iki boyutlu yapısı (akademik mobbing ve akademik olmayan mobbing) ortaya çıkmıștır. Diğer taraftan, öğrencilerin tükenmişliğini ölçmek için "Maslach Tükenmişlik Envanteri-Öğrenci” kullanılmıştır. Daha sonra çalışmanın amacı doğrultusunda değişkenler arasındaki ilişkiler hiyerarşik regresyon analizi ile incelenmiştir. Sonuçlar mobbing davranışlarının öğrenci tükenmişliğini anlamlı ve pozitif yönde etkilediğini göstermiştir $(\beta=, 350 ; p<0,01)$.

Anahtar kelimeler: Mobbing, Öğrenci Tükenmişliği, Lisans, Üniversite

\section{The Effect of Mobbing Behaviors on Students' Burnout: An Empirical Study on Undergraduate Students of the Faculty of Sports Sciences}

\begin{abstract}
Numerous variables influence student burnout, one of which is mobbing. In this study, the effect of mobbing behaviors on undergraduate students' burnout was investigated. The data were obtained from students of a faculty of sports sciences $(\mathrm{n}=223)$. To measure mobbing, we used a modified version of the Negative Acts Questionnaire-Revised (NAQ-R: Einarsen et al., 2009) adapted to the higher education context. The new version of this scale was developed in this study, and it was labeled as the Negative Acts Questionnaire-Student (NAQ-S). For the validity of the scale, both exploratory factor analysis and confirmatory factor analysis were applied. In addition, Cronbach's alpha coefficient was calculated for the reliability of the scale. The validity and reliability analyzes showed high values. As a result, NAQ-S contained 12 items (see the appendix) and a two-factor structure: academic mobbing (1-4 items) and non-academic mobbing (5-12 items). On the other hand, to measure students' burnout, Maslach Burnout Inventory-Student Survey (MBI-SS: Schaufeli et al., 2002) was used. Then, hierarchical regression analysis was used to investigate the relationships between variables. The results showed that mobbing behaviors had a significant and positive effect on students' burnout $(\beta=.350 ; p<0.01)$.

Keywords: Mobbing, Students' Burnout, Undergraduate, University.
\end{abstract}

*Bu çalışma 26-27 Ekim 2019 tarihleri arasında Kuşadası'nda düzenlenen 9. Uluslararası Balkanlarda Sosyal Bilimler Kongresi’nde sözel bildiri olarak sunulmuştur.

†Sorumlu Yazar: Süleyman Murat YILDIZ, Doç. Dr., E-posta: smyildiz@ gmail.com. 
Yıldız, S.M. (2020). Mobbing davranışlarının öğrenci tükenmişliğine etkisi: Spor Bilimleri Fakültesi lisans öğrencileri üzerinde ampirik bir inceleme. Spor Bilimleri Araştırmaları Dergisi, 5(1), 1-14.

\section{GíRiş}

Son yıllarda literatürde mobbing ve tükenmişlik ile ilgili araştırmaların arttığı görülmektedir. $\mathrm{Bu}$ artışın nedeni hem mobbingin hem de tükenmişliğin örgütlerde gün geçtikçe daha sık görülmesi ve bireyler üzerinde olumsuz etki yaratmasıdır (Karık ve Yıldız, 2015; Varhama ve Björkqvist, 2004).

Mobbing, bir başkasına kasten zarar vermek ve onu rahatsız etmek için üretilen agresif bir davranış olarak ifade edilirken (Leymann, 1996), tükenmişlik, aşırı ve kronik stresin neden olduğu psikolojik sendrom olarak tanımlanmaktadır (Maslach, 2003). Hem mobbing hem de tükenmişlik, bireylerin örgütlerdeki verimliliğini olumsuz yönde etkileyen olgulardır (Maslach ve Leiter, 2008; Notelaers vd., 2006). Son zamanlarda yapılan araştırmalarda, örgütlerde mobbing ve tükenmişliğin yarattığı olumsuz psikolojik iklimin artma eğiliminde olduğu görülmüştür (Y1ldız, 2015).

Mobbing eğitim örgütlerinde de görülen ve sürekli gelişen bir olgudur. Geçtiğimiz yıllarda, ilkokul (örneğin, Wolke vd., 2001), ortaokul (örneğin, Alex-Hart, Okagua ve Opara, 2015) ve lise (Taştan ve Gökler, 2017) düzeyinde kapsamlı çalışmalar yapılmıştır. Ancak, yükseköğretimde mobbing araştırmaları sınırlıdır (Giovazoalias ve Malikiosi-Loizos, 2015). Örneğin, Hoover, Oliver ve Hazler (1992), mezun öğrencilerin yarısından fazlasının okul yaşamı boyunca farklı türlerde mobbing davranışı ile yüzyüze geldiklerini bildirmiştir. Lisansüstü öğrenciler üzerinde yapılan bir çalışmada, öğrencilerin \%20'den fazlasının danışmanları tarafından mobbinge maruz bırakıldıkları ortaya konulmuştur (Yamada, Cappadocia ve Pepler, 2014). Giovazoalias ve Malikiosi-Loizos (2015) ise öğrenciler ile öğretim elemanları arasında mobbing davranışları üzerine yapılan araştırmaların oldukça sinırlı olduğunu belirtmektedir.

Son zamanlarda çeşitli mesleklerde stres ve tükenmişlik üzerine yapılan araştırmalara öğrenciler de eklenmiştir (Yıldız ve Dirik, 2019). Öğrencilerin üniversite hayatı incelendiğinde, bir çalışan olmasa da, onların akademik çabaları bir nevi iş olarak kabul edilebilir. Bu nedenle, öğrencilerin iş yükünü (sınıf içi etkinlikler, ev ödevleri, sınavlar vb.) başarıyla tamamlamaları gerekmektedir (Salmela-Aro, Savolainen ve Holopainen, 2009). Üniversite öğrencileri akademik yaşamlarında, bir taraftan eğitim desteği alırken (Yıldız ve Tüfekçioğlu, 2008), diğer taraftan çeşitli nedenlerden kaynaklanan olumsuz durumlarla, örneğin akademik tükenmişlikle karşı karşıya kalabilir. Bu bağlamda, düşük öz yeterlik (Rahmati, 2015), yüksek iş yükü (Jacobs ve Dodd, 2003), iş yükü kontrol eksikliği, ödül eksikliği ve sosyal destek eksikliği (Maslach ve Leiter, 2008) öğrencilerin tükenmişliği üzerinde önemli etkiye sahip olabilir. Öte yandan, mobbing davranışları öğrencilerin tükenmişliğini de etkileyebilir. Literatüre göz atıldığında, yükseköğretimde mobbing davranışı ile öğrenci tükenmişliği arasındaki ilişkinin sonucunda ortaya çıkan bilgilerin oldukça sınırlı olduğu görülmektedir (Giovazoalias ve Malikiosi-Loizos, 2015; Goodboy, Martin ve Johnson, 2015). Bu nedenle, bu çalışmada, yükseköğretim bağlamında öğretim elemanı kaynaklı mobbing davranışlarının öğrenci tükenmişliği üzerindeki etkisinin incelenmesi amaçlanmıştır.

$\mathrm{Bu}$ makalede ilk olarak kavramsal olarak mobbing ve tükenmişlik konularına değinilmiş, ardından araştırma hipotezleri ve ana hatlarıyla araştırma metodolojisi hakkında bilgiler 
Yıldız, S.M. (2020). Mobbing davranışlarının öğrenci tükenmişliğine etkisi: Spor Bilimleri Fakültesi lisans öğrencileri üzerinde ampirik bir inceleme. Spor Bilimleri Araştırmaları Dergisi, 5(1), 1-14.

verilmiştir. Daha sonra araştırma bulguları sunulmuş ve son olarak da araştırmanın etkileriyle ilgili sonuçlar ortaya konulmuştur.

\section{Mobbing}

Mobbinge ilk olarak değinen Avusturyalı bilim adamı Etolojist Konrad Lorenz (1963) olmuştur. Bu kavramı "bir grup hayvanın tek bir hayvanı çeşitli şekillerde hedef alarak korkutması, ona zarar vermesi” şeklinde kullanmıştır. Daha sonra Heinemann (1972) bu kavramı, bir grup çocuğun diğer bir grup çocuğa zarar vermesiyle ilgili grup davranışlarını incelerken ele almıştır. Esasında, mobbinge yönelik algı uzun süredir var olmasına rağmen, işyerindeki varlığı ve etkilerinin bilimsel olarak incelenmesi son yirmi yıla dayanmaktadır. Son yllarda mobbing konusuna daha sık değinilmesinin altında nadir görülen bir olay olmaktan çıkıp işyerinde yaygın hale gelmesi yatmaktadır (Vandekerckhove ve Commers, 2003). Örgütlerde mobbingin olumsuz psikolojik etkileri üzerine bir dizi çalı̧̧ma yürüten Leymann (1996), bu alanda öncü bir araştırmacı olarak görülebilir. Leymann çalışmalarında, mobbing davranış formlarının niteliklerine ve bu davranışa maruz kalanların üzerindeki psikolojik etkilerine odaklanmıştır. Leymann tanımladığı 45 ayrı mobbing davranışını özelliklerine göre beş grupta sınıflamıştır. Bunlar; kişinin saygınlığına saldırı (amaç; küçümseme, karalama ve itibarsızlaştırma), performansa yönelik saldırılar (amaç; iş başarımını düşürme), iletişime yönelik saldırılar (amaç; iletişim bağlarını koparma), sosyal koşullara yönelik saldırılar (amaç; sosyal bağları koparma, tecrit etme) ve fiziksel saldırı tehdidi (amaç; fiziksel sağlığı etkileme), (Yıldız, 2017:150).

Mobbing olgusu "zorbalık, psikolojik taciz, psikolojik terör, yıldırma, psikolojik şiddet, iş yeri terörü” gibi kavramlarla da ifade edilmektedir (Y1ldız, 2017:145). Esasında tüm bu terimlerin hepsi bir kişiye karşı gerçekleştirilen bir nevi şiddet eylemine odaklanmaktadır. Leymann (1996) mobbingi "örgütlerde, bir veya birkaç kişinin genelde tek bir kişiye sistematik bir şekilde yönelttiği, kişiyi çaresiz ve savunmasız bir durumun içine iten düşmanca veya ahlak dışı davranışlar" olarak tanımlamıştır. Einarsen, Hoel ve Notelaers (2009) ise mobbingi "bireyin performans yeteneğini olumsuz yönde etkileyen taciz içerikli sosyal dışlama davranışları" olarak ifade etmiştir.

Mobbing, tüm mesleklerde ve örgütlerde ortaya çıkabilen (Vveinhardt, Fominiene, ve Andriukaitiene, 2019), kültür ve cinsiyet farkı gözetmeksizin herkesin maruz kalabileceği, sonuçları ağır bir durumdur (Tınaz, 2006). Mobbing davranışına maruz kalan bireyde; bir taraftan düşük verimlilik (Öntürk, 2018) ve düşük ekstra rol davranışı (Yıldız, 2016) gibi durumlar görülürken, diğer taraftan yüksek stres ve tükenmişlik görülebilir (Yıldız, 2017).

\section{Tükenmişlik}

Maslach (2003) tükenmişliği "işyerinde stresörlerin uzun etkileri ile ortaya çıkan bir psikolojik sendrom" olarak tanımlamış ve bu durumu iş ile çalışan arasındaki uyumsuzluktan kaynaklanan kronik bir gerginlik olarak görmüştür. Tükenmişlik yaşayan kişiler düşük enerji, motivasyonsuzluk, işine ve başkalarına karşı negatif hisler besleme ve kişiler arası etkileşimden kaçınma gibi durumlarla yüz yüze kalmaktadırlar (Thomas ve Lankau, 2009).

Eğitim öğretim bağlamında değerlendirildiğinde öğrencilerin derslere katılımları, ödevler ve sınavlarda talep edilenleri yerine getirme çabaları bir iş olarak kabul edilmektedir. $\mathrm{Bu}$ 
nedenle iş ortamında görülen tükenmişlik olgusu, eğitim ortamında öğrenciler üzerinde de görülebilmektedir (Schaufeli ve Taris, 2005). Her meslekte görülebilen bir olgu olan tükenmişliği Schaufeli ve diğerleri (2002) yükseköğretimdeki öğrenciler üzerinde incelemiştir. Araştırmacılar öğrenci tükenmişliğini "tükenme, sinizm ve mesleki etkinlik" olmak üzere üç boyutta ele almışlardır. Goodboy ve diğerleri (2015) bu boyutları şu şekilde açıklamışlardır: "Tükenme, yorgunluk ve stress nedeniyle duygusal kaynakların tükenmesi ile oluşan enerji eksikliği ile karakterizedir. Sinizm, genel olarak işe yönelik uzak veya kayıtsız bir tutuma sahip olmayı ifade eder. Mesleki etkinlik, sosyal ve mesleki başarılara sahip olma anlamına gelir; mesleki etkinlik eksikliği, kişisel başarıların azaldığını ve işle ilgili görevlerde daha düşük bir başarı seviyesini yansıtır (s.273).”

Yükseköğretim bağlamındaki bazı değişkenler öğrenci tükenmişliği ile ilgilidir. Önceki araştırmalar düşük öz yeterlik, iş yükü, zaman baskısı, olumsuz öğrenci-öğretmen ilişkilerinin öğrenci tükenmişliğinin başlica öncüleri olduğunu göstermiştir (Furrer, Skinner ve Pitzer, 2014; Pienaar ve Sieberhagen, 2005; Rahmati, 2015). Son zamanlarda yapılan bir araştırma, mobbingin öğrenci tükenmişliğinin de öncülü olabileceğini göstermiştir (Goodboy vd., 2015). Öte yandan, öğrenci tükenmişliğinin en önemli sonuçları düşük motivasyon ve düşük akademik başarıdır. Bazı araştırmalar, akademik başarı ile öğrenci tükenmişliği arasında negatif bir ilişki olduğunu göstermiştir (McCarthy, Pretty ve Catano, 1990; Yang, 2004).

Tükenmişliği açıklamakta en etkili modellerden biri iş yükü-kontrol modelidir. Bu model iş durumunun yönlerini ve iş taleplerini stres ile ilişkilendirmektedir. Bu modele göre, iş yükü ve iş kontrolü arasındaki etkileşim işten kaynaklanan stres düzeyini belirlemektedir (Karasek, 1979). $\dot{I}_{S}$ yükü, belirli bir zamanda belirli bir kalitede yapılması gereken iş miktarını; kontrol ise, bu işin, çalışanın bilgi, beceri, yetenek ve kararları ile doğru ve amaca uygun bir şekilde yerine getirebilmesini ifade eder. İş yükü ile kontrol arasındaki fark stres düzeyini belirlemektedir. Eğer fark yok ise, iş ile ilişkili bir stresten bahsedilemez. Eğer fark varsa stresten bahsedilebilir ve özellikle bu farkın artması stres düzeyini artırır. Hem stres düzeyinin yüksek olması, hem de stresin kronikleşmesi tükenmişliğin oluşmasında önemli rol oynamaktadır. İş yüküne karşı bireyin kontrol güçlügü çekmesi durumunda çevresinden gelecek yeterli "sosyal destek" bireyin iş stresini hafifleten önemli bir etkendir (Yıldız, 2017:177). Sosyal destek, tükenmişliği açıklamada etkili çevresel faktörlerden biri olarak görülebilir. Sosyal destek, bir bireye çevresindeki kişilerden gerekli bilgi ve psikolojik yardım sağlanmasıdır. Eğitim ortamında, öğrenciler öğretmenlerden, sınıf arkadaşlarından ve yakın arkadaşlarından sosyal destek alabilir. Eğitim ortamında öğrencilere yeteri kadar sosyal desteğin sunulmaması, öğrencilerin tükenmişlik yaşama olasılığını arttırmaktadır (Jacobs ve Dodd, 2003).

\section{Mobbing ve Öğrenci Tükenmişliği Arasındaki İlişsi}

Öğrencilerde tükenmişlik iki açıdan ele alınabilir. Birincisi iş yükünü kontrol edemeyen öğrenci tükenmişlik yaşar. Burada akademik yetersizlik söz konusudur, dolayısıyla öğrencinin iş kaynaklı olarak öğrenim düzeyini kaldıramadığı söylenebilir. İkincisi mobbing kaynaklı tükenmişliktir ki, burada öğrencinin iş yükünü kontrol edebilme yeteneği vardır, ancak uygulanan mobbing yüzünden öğrenci motivasyonunu kaybeder. 
Yükseköğretim ortamında mobbing ve tükenmişlik olgularını ayrı ayrı ele alan çalışmalar oldukça yaygın olmasına rağmen, her iki olgu arasındaki ilişkiyi öğrenci bağlamında inceleyen araştırmalar oldukça sınırlıdır (Giovazoalias ve Malikiosi-Loizos, 2015; Goodboy vd., 2015). Bu bağlamda yapılan bir araştırmada, Goodboy ve diğerleri (2015) bir yükseköğretim kurumunda lisansüstü öğrenciler üzerinde mobbing ile tükenmişlik arasındaki ilişkiyi incelemiştir. Araştırma bulguları mobbing ile öğrenci tükenmişliği arasında pozitif ilişki olduğunu göstermiş̧ir. Sınırlı olan çalışmalara karşın, daha fazla araştırma yapılarak, mobbing ve öğrenci tükenmişliği arasındaki ilişkinin yükseköğretim bağlamında daha fazla netleştirilmesi gerektiği açıktır. Dolayısıyla, literatüre katkı sağlamak amacıyla, mobbingin öğrenci tükenmişliği üzerine olan etkisine yönelik aşağıdaki hipotezler geliştirilmiştir:

$H_{l}$. Akademik mobbingin lisans öğrencilerinin tükenmişliği üzerinde anlamlı ve pozitif bir etkisi vardır.

$H_{2}$. Akademik olmayan mobbingin lisans öğrencilerinin tükenmişliği üzerinde anlamlıve pozitif bir etkisi vardır.

$H_{3}$. Mobbingin lisans öğrencilerinin tükenmişliği üzerinde anlamlı ve pozitif bir etkisi vardır.

\section{YÖNTEM}

$\mathrm{Bu}$ çalışmada nitel yaklaşım ve nicel ölçek uygulamasını içeren iki aşamalı bir metodoloji kullanılmışır. Çalışmanın ilk aşamasında, öğrencilere yönelik mobbingi ölçmek için ölçek maddeleri geliştirmiş, ardından ikinci aşamada mobbingin tükenmişliğe olan etkisi ampirik olarak test edilmiştir.

\section{Örneklem}

Bu çalışmada kullanılan veriler, Türkiye'de bulunan bir devlet üniversitesinin spor bilimleri fakültesindeki öğrencilerinden $(\mathrm{n}=223)$ elde edilmiştir. Kolayda örnekleme yöntemi kullanılarak, öğrencilere 280 ölçek formu dağıtılmış, uygulama sonunda 242 ölçek formunun geri döndüğü (geri dönüş oranı \%86,4) görülmüştür. Eksik doldurulan 19 form değerlendirilmeye alınmamış, sonuçta 223 form analiz için uygun bulunmuştur.

\section{Ölçme Araçları}

Mobbing Ölçeği: Öğretim elemanı kaynaklı mobbing davranışlarını ölçmek için, Einarsen ve diğerleri (2009) tarafından geliştirilen "Negatif Davranışlar Ölçeği (NDÖ)" bu çalışmada öğrenci bağlamına dönüştürülmüştür. Orijinal ölçekteki ifadelerin öğrencilere uymamasından dolayı, ölçüm özelliklerini sağlamak için, orijinal ölçeğin üniversite ortamına uyarlanmasına gerek duyulmuştur. 16 üniversite öğrencisinden oluşan bir odak grubun katılımıyla, derinlemesine görüşme ve beyin firtınası tekniği kullanılarak, her bir ölçek maddesi üniversite ortamına yönelik anlamlılığı bakımından incelenmiş̧tir. Ayrıca, odak grup görüşmesinde Leymann'ın (1996) "Leymann Inventory of Psychological Terrorization" çalışması da ele alınarak, üniversitede mobbingin en etkili şekilde ölçülmesini sağlayabilecek potansiyel ölçek maddeleri de görüşülmüştür. Bu süreçte örneğin, NDÖ'de bulunan "bilgisini saklayan biri performansınızı etkiler" maddesi "öğretim elemanının sahip olup da size vermediği kritik bilgiler akademik performansınızı etkiler" ifadesine dönüştürülmüşsür. Derinlemesine görüşmeler doyum noktasına ulaştığında, 12 maddeli bir ölçek ortaya çıkmış ve buna Negatif Davranışlar Ölçeği-Öğrenci (NDÖ-Ö) adı verilmiştir. Daha sonra, küçük bir 
Yıldız, S.M. (2020). Mobbing davranışlarının öğrenci tükenmişliğine etkisi: Spor Bilimleri Fakültesi lisans öğrencileri üzerinde ampirik bir inceleme. Spor Bilimleri Araştırmaları Dergisi, 5(1), 1-14.

pilot test uygulaması ile, ölçek ifadelerinde olabilecek sorunları araştırmak ve düzeltmek için NDÖ-Ö 30 öğrenciye uygulanmıştır. Uygulama sonunda ifadelerde küçük düzeltmeler yapılmış ve ölçek formu son haline getirilmiştir (EK 1).

Öğrenci Tükenmişliği Ölçeği: Öğrencilerin tükenmişliğini ölçmek için, Maslach Tükenmişlik Envanteri'nin Schaufeli ve diğerleri (2002) tarafından öğrenci versiyonuna dönüştürülmüş hali olan "Maslach Tükenmişlik Envanteri-Öğrenci” (MTE-Ö) kullanılmıştır. Öğrencilere yönelik olan bu ölçme aracı 15 maddeden ve 3 boyuttan (tükenme, sinizm, mesleki etkinlik) oluşmaktadır. Orijinal ölçeğin Türkçe versiyonunu oluşturmak için maddelerin çevirisinde Brislin'in (1970) geri tercüme yöntemi kullanılmıştır. Geri çeviri yöntemi kültürlerarası araştırmalarda çeviri için en yaygın ve en çok önerilen yaklaşımdır. Bu yöntem çerçevesinde her ölçek maddesi İngilizceden Türkçeye çevrilmiş ve alan uzmanları tarafından çapraz kontrol edilip değerlendirilmiştir. Gerekli düzeltmeler yapıldıktan sonra, düzenlenen form katılımcılara uygulanmıştır.

Her iki ölçek maddeleri "1=hiçbir zaman, 2=çok nadir, 3=bazen, 4=çoğu zaman, 5=her zaman” arasında değişen beş noktalı Likert tipi bir ölçekle ölçülmüştür.

\section{İstatistiki Analiz}

Ölçeklerin yapı geçerliliğini tespit etmek için açımlayıcı faktör analizi (AFA) ve doğrulayıcı faktör analizi (DFA) kullanılmıştır. Ölçeklerin güvenirliklerini değerlendirmek için Cronbach's alfa katsayıları hesaplanmıştır. Değişkenler arasındaki ilişkileri belirlemek için korelasyon analizi, mobbingin tükenmişlik üzerindeki varsayımsal etkilerini test etmek için hiyerarşik regresyon analizi kullanılmıştır. Ayrıca, mobbing ve tükenmişliğin varlığı ile ilgili değerlendirmeler şu puan aralıklarına göre yapılmıştır: 1,00 - 1,79 arası = hiç yok; 1,80 - 2,59 aras1 = çok nadir; 2,60 - 3,39 aras1 = bazen; 3,40 - 4,19 aras1 = çoğu zaman; 4,20 - 5,00 aras1 $=$ her zaman.

\section{BULGULAR}

\section{Demografik Özellikler}

Çalışmaya katılan öğrencilerin ( $\mathrm{n}=223)$ demografik özellikleri Tablo 1'de sunulmuştur.

Tablo 1: Öğrencilerin demografik özellikleri

\begin{tabular}{llcc}
\hline Değişkenler & & $\mathbf{f}$ & \% \\
\hline \multirow{3}{*}{ Cinsiyet } & Erkek & 128 & 57,4 \\
& Kadın & 95 & 42,6 \\
& Toplam & 223 & 100 \\
\hline \multirow{3}{*}{ Sinıf } & Birinci & 51 & 22,9 \\
& İkinci & 54 & 24,2 \\
& Üçüncü & 60 & 26,9 \\
& Dördüncü & 58 & 26,0 \\
& Toplam & 223 & 100 \\
\hline Yaş & & $\mathbf{X}$ & SS \\
\hline
\end{tabular}


Yıldız, S.M. (2020). Mobbing davranışlarının öğrenci tükenmişliğine etkisi: Spor Bilimleri Fakültesi lisans öğrencileri üzerinde ampirik bir inceleme. Spor Bilimleri Araştırmaları Dergisi, 5(1), 1-14.

Verilerin demografik analizi, katılımcıların yaş ortalamasının 21,5 2,01 olduğunu göstermiştir. Öğrencilerin çoğunluğunu erkekler $(\% 57,4)$ oluşturmuştur. Katılımcıların \%22,9’u birinci sınıf öğrencisi (n=51), \%24,2'si ikinci sınıf öğrencisi (n=54), \%26,9’u üçüncü sınıf öğrencisi $(n=60)$ ve \%26’sı ise dördüncü sinıf $(n=58)$ öğrencisidir.

\section{Geçerlik ve Güvenirlik Sonuçları}

\section{Negatif Davranışlar Ölçeği-Öğrenci’nin Geçerlik ve Güvenirlik Sonuçları}

AFA sonuçları NDÖ-Ö’nün iki boyutlu yapısını ortaya koymuştur. Her boyutta yer alan maddelere yüklenen anlamlara dayanarak bu boyutlara "akademik mobbing" ve "akademik olmayan mobbing” ismi verilmiştir. KMO katsayısı $(0,890)$ ve Bartlett'in Sphericity testi $\left(\chi^{2}=999,541 ; \mathrm{p}<0,001\right)$ faktör analizinin uygun olduğunu göstermiştir. Ayrıca, ölçeğin Cronbach's alfa değeri $(\alpha=0,831)$ oldukça yüksektir. Tablo 2 , faktör yükleri ve yapının boyutluluğuna yönelik bazı istatistiki değerleri göstermektedir. Ayrıca, ölçeğe uygulanan DFA'da güçlü model uyumu indeksleri $\left(\chi^{2}=121,8 ; \mathrm{df}=53 ; \chi^{2} / \mathrm{df}=2,29 ; \quad\right.$ CFI=0,928; $\mathrm{GFI}=0,918$; AGFI=0,879; IFI=0,929; RMESA=0,076) gözlenmiştir. Bu modeldeki değerler, literatürde önerilen kriterleri karşılamaktadır (Browne ve Cudeck, 1993; Byrne, 2001).

Tablo 2: Negatif Davranışlar Ölçeği-Öğrenci'nin geçerlik ve güvenirlik sonuçları

\begin{tabular}{|c|c|c|c|c|}
\hline Maddeler & $\boldsymbol{X}$ & $S D$ & F1 & F2 \\
\hline $\begin{array}{l}\text { 1. Öğretim elemanının sahip olup da size vermediği kritik bilgiler akademik } \\
\text { performansınızı etkiler. }\end{array}$ & 3,72 & 1,29 & & ,705 \\
\hline $\begin{array}{l}\text { 2. Öğretim elemanı akademik yetkinlik seviyenizin üzerindeki işi (ödev, } \\
\text { araştırma proje vb.) yapmaya zorlar. }\end{array}$ & 2,78 & 1,23 & & ,773 \\
\hline 3. Öğretim elemanı akademik fikirlerinizi önemsemez. & 1,99 & 1,19 & & 601 \\
\hline 4. Öğretim elemanı kaldıramayacağınız derecede iş yoğunluğu verir. & 1,74 & 1,03 & & 610 \\
\hline 5. Öğretim elemanı yaptığınız işle dalga geçer. & 1,32 &, 77 & ,727 & \\
\hline 6. Öğretim elemanı tarafından göz ardı edilir ve dışlanırsınız. & 1,41 & 84 & 627 & \\
\hline 7. Öğretim elemanı kişiliğiniz/özel hayatınız hakkında aşağılayıcı sözler söyler. & 1,24 &, 71 & ,776 & \\
\hline 8. Hatalarınız ve yanlışlarınız öğretim elemanı tarafından sürekli hatırlatılır. & 1,80 & 1,05 & 640 & \\
\hline 9. Öğretim elemanı hakkınızda suçlamalarda bulunur. & 1,36 &, 83 & ,814 & \\
\hline 10. Size karşı öğretim elemanı tarafından anlık kızmalar ve bağırmalar olur. & 1,74 & ,93 & 668 & \\
\hline 11. Öğretim elemanı size korkutucu davranışlar sergiler. & 1,31 & ,71 & ,781 & \\
\hline 12. Öğretim elemanı tarafından şiddetli olarak tehdit edilirsiniz. & 1,16 &, 60 & ,791 & \\
\hline ( & 1,99 & & 1,42 & 2,56 \\
\hline$S D$ & & 60 &, 59 & ,83 \\
\hline Percentage of Variance Explained & & & 38,166 & 16,739 \\
\hline Cumulative $\%$ of Variance Explained & & & 38,166 & 54,905 \\
\hline Cronbach's Alpha & & & 0,873 & 0,650 \\
\hline & & & \multicolumn{2}{|c|}{0,831} \\
\hline
\end{tabular}

F1= Akademik Olmayan Mobbing, F2= Akademik Mobbing

\section{Maslach Tükenmişlik Envanteri-Öğrenci’nin Geçerlik ve Güvenirlik Sonuçları}

AFA sonuçlarına göre MTE-Ö’nün faktör yükleri 0,564 ile 0,882 arasında değişmektedir. KMO katsayıs1 $(0,886)$ ve Bartlett'in Sphericity testi $\left(\chi^{2}=1867,660 ; p<0,001\right)$ faktör analizinin uygun olduğunu göstermiştir. Ayrıca, ölçeğin Cronbach's alfa değeri $(\alpha=0,789)$ oldukça yüksek bulunmuştur. Diğer taraftan, ölçeğe uygulanan DFA'da güçlü model uyumu indeksleri $\left(\chi^{2}=161,0 ; \mathrm{df}=87 ; \chi^{2} / \mathrm{df}=1,85 ; \mathrm{CFI}=0,959\right.$; GFI=0,914; AGFI=0,881; IFI=0,960; RMESA=0,062) gözlenmiştir. $\mathrm{Bu}$ modeldeki değerler, literatürde önerilen kriterleri karşılamaktadır (Browne ve Cudeck, 1993; Byrne, 2001). 
Yıldız, S.M. (2020). Mobbing davranışlarının öğrenci tükenmişliğine etkisi: Spor Bilimleri Fakültesi lisans öğrencileri üzerinde ampirik bir inceleme. Spor Bilimleri Araştırmaları Dergisi, 5(1), 1-14.

\section{Mobbing ve Öğrenci Tükenmişliği Düzeyleri}

Mobbinge yönelik aritmetik ortalamaya bakıldığında, bu tür davranış varlığının "çok nadir" düzeyde olduğu $(X=1,99)$ görülmektedir. Diğer taraftan alt boyutlara bakıldığında akademik mobbingin "bazen" seviyesinde $(X=2,56)$, akademik olmayan mobbingin "çok nadir" düzeyde $(X=1,42)$ olduğu görülmektedir. Tükenmişliğe yönelik aritmetik ortalamaya bakıldığında ise, öğrenci tükenmişliğinin “bazen” seviyesinde olduğu $(X=2,74)$ görülmektedir (Tablo 3).

Tablo 3: Mobbing ve öğrenci tükenmiş̧liği düzeyleri

\begin{tabular}{lcc}
\hline & $X$ & $S D$ \\
\hline Mobbing & 1,99 &, 60 \\
Akademik mobbing & 2,56 &, 83 \\
Akademik olmayan mobbing & 1,42 &, 59 \\
Öğrenci tükenmişliği & 2,74 &, 55 \\
\hline
\end{tabular}

\section{Korelasyon Analizi Sonuçları}

Korelasyon analizi, mobbing ve tükenmişlik arasında anlamlı ve pozitif bir ilişkinin olduğunu göstermiştir $(r=0,341 ; p<0,01)$. Yani, mobbing davranışı arttıkça tükenmişlik de artmaktadır. Demografik değiş̧kenlere göz atıldığında, hiçbir demografik değişkenin tükenmişlik ile anlamlı ilişkisi yok iken, cinsiyetin ve sınıf düzeyinin mobbing ile ilişkisi bulunmaktadır. Cinsiyet değişkeninde mobbing davranışı kadınlar lehine azalmaktadır. Sınıf düzeyi arttıkça mobbing davranışı artmakta, ancak iki değişken arasındaki bu ilişkinin zayıf düzeyde olduğu da görülmektedir (Tablo 4).

Tablo 4: Korelasyon analizi sonuçları

\begin{tabular}{lcccccc}
\hline Değişkenler & $\mathbf{1}$ & $\mathbf{2}$ & $\mathbf{3}$ & $\mathbf{4}$ & $\mathbf{5}$ & $\mathbf{6}$ \\
\hline 1. Cinsiyet & 1 & & & & & \\
2. Yaş &,- 131 & 1 & & & & \\
3. Sınıf &,- 010 &, $544^{* *}$ & 1 & & & \\
4. Akademik mobbing &,- 115 &, $152^{*}$ &, $200^{* *}$ & 1 & & \\
5. Akademik olmayan mobbing &,- 128 &, 035 &, 084 &, $393^{* *}$ & 1 & \\
6. Mobbing &,$- 150^{*}$ &, 093 &, $142^{*}$ &, $727^{* *}$ &, $908^{* *}$ & 1 \\
7. Tükenmişlik &,- 018 &, 055 &, 022 &, $197^{* *}$ &, $352^{* *}$ &, $341^{* *}$ \\
\hline${ }^{* *} p<0,01 ;{ }^{*} p<0,05$ & & & & & &
\end{tabular}

\section{Hiyerarşik Regresyon Analizi Sonuçları}

$\mathrm{Bu}$ çalışmada, geliştirilen hipotezleri test etmek amacıyla, tükenmişliğin bağımlı değişken olarak ele alındığı hiyerarşik regresyon analizi uygulanmıştır. Analiz sonuçları, mobbingin öğrencilerin tükenmişliği üzerinde anlamlı ve pozitif etkisinin $(\beta=, 350 ; p<0,01)$ olduğunu göstermiştir (Tablo 7). Ayrıca hem akademik mobbingin $(\beta=, 200 ; p<0,01)$ hem de akademik olmayan mobbingin $(\beta=, 358 ; \mathrm{p}<0,01)$ öğrenci tükenmişliğini anlamlı ve pozitif olarak etkilediği de bulunmuştur (Tablo 5, 6). Bu sonuçlara göre, bu çalışmada ele alınan üç hipotez de kabul edilmiştir. 
Yıldız, S.M. (2020). Mobbing davranışlarının öğrenci tükenmişliğine etkisi: Spor Bilimleri Fakültesi lisans öğrencileri üzerinde ampirik bir inceleme. Spor Bilimleri Araştırmaları Dergisi, 5(1), 1-14.

Tablo 5: Akademik mobbingin tükenmişlik üzerine etkisine yönelik hiyerarşik regresyon analizi sonuçları

\begin{tabular}{lcc}
\hline Bağımsız değişkenler & \multicolumn{2}{c}{ Tükenmişlik } \\
\cline { 2 - 3 } & Adım 1 & Adım 2 \\
\hline 1. Cinsiyet &,- 010 &, 012 \\
2. Yaş &, 060 &, 052 \\
3. Sınıf &,- 011 &,- 046 \\
4. Akademik mobbing & - &, $200^{*}$ \\
F &, 239 & 2,333 \\
$R^{2}$ &, 003 &, 041 \\
Adjusted $R^{2}$ &,- 010 &, 023 \\
\hline
\end{tabular}

Not: Standardize edilmiş beta değerleri kullanılmıştır, " $p<0,01$

Tablo 6: Akademik olmayan mobbingin tükenmişlik üzerine etkisine yönelik hiyerarşik regresyon analizi sonuçları

\begin{tabular}{lcc}
\hline Bağımsız değişkenler & \multicolumn{2}{c}{ Tükenmişlik } \\
\cline { 2 - 3 } & Adım 1 & Adım 2 \\
\hline 1. Cinsiyet &,- 010 &, 037 \\
2. Yaş &, 060 &, 074 \\
3. Sinıf &,- 011 &,- 048 \\
4. Akademik olmayan mobbing & - &, $358^{*}$ \\
F &, 239 & 8,026 \\
$R^{2}$ &, 003 &, 128 \\
Adjusted $R^{2}$ &,- 010 &, 112 \\
\hline
\end{tabular}

Not: Standardize edilmiş beta değerleri kullanılmıştır, ${ }^{*} p<0,01$

Tablo 7: Mobbingin Tükenmişlik üzerine etkisine yönelik hiyerarşik regresyon analizi sonuçları

\begin{tabular}{lcc}
\hline Bağımsız değişkenler & \multicolumn{2}{c}{ Tükenmişlik } \\
\cline { 2 - 3 } & Adım 1 & Adım 2 \\
\hline 1. Cinsiyet &,- 010 &, 042 \\
2. Yaş &, 060 &, 062 \\
3. Sınıf &,- 011 &,- 061 \\
4. Mobbing & - &, $350^{*}$ \\
F &, 239 & 7,495 \\
$R^{2}$ &, 003 &, 121 \\
Adjusted $R^{2}$ &,- 010 &, 105 \\
\hline \multicolumn{2}{c}{ Not: Standardize edilmiş beta değerleri kullanılmıştır, ${ }^{*} p<0,01$} &
\end{tabular}

\section{TARTIŞMA VE SONUÇ}

Bu çalışmanın nitel olan ilk aşamasında, mobbingi ölçmek için öğrencilere yönelik özel ölçek maddeleri geliştirilmiştir. Bu çerçevede, Einarsen ve diğerleri (2009) tarafından geliştirilen "Negatif Davranışlar Ölçeği” bu çalışmada öğrenci bağlamına dönüştürülmüştür. Orijinal ölçekteki ifadelerin öğrencilere uymamasından dolayı, ölçüm özelliklerini sağlamak için, orijinal ölçeğin üniversite ortamına uyarlanmasına gerek duyulmuştur. Yapılan analizler NDÖ-Ö’nün yükseköğretim ortamında mobbingi ölçmek için geçerli ve güvenilir bir araç olduğunu ortaya çıkarmıştır. Lisansüstü öğrencilere yönelik bir araştırmada, Goodboy ve diğerleri (2015) mobbingi ölçmek için Einarsen ve diğerleri (2009) tarafından geliştirilen "Negatif Davranışlar Ölçeği”ni kullanmışlardır. Ancak bu araştırmacılar, iş yerinde çalışanlar için geliştirilen bu ölçeğin öğrencilere yönelik nasıl kullanıldığını araştırmalarında net olarak belirtmemişlerdir.

$\mathrm{Bu}$ çalışmanın ikinci aşamasında, öğretim elemanı kaynaklı mobbing davranışının öğrenci tükenmişliği üzerindeki etkisi incelenmiştir. Yükseköğretimde mobbing (örneğin, Metzger, Petit ve Sieber, 2015) ve tükenmişlik (Örneğin, Neumann, Finaly-Neumann ve Reichel, 1990) konularını ayrı ayrı ele alan çalışmalar oldukça fazladır. Ancak, her iki değişken 
arasındaki ilişkiyi farklı eğitim seviyelerinde inceleyen araştırmalar ise oldukça sınırlıdır. Özellikle, her iki yapının spor bilimleri fakültesindeki öğrenciler üzerindeki ilişkisini araştıran herhangi bir çalışmaya rastlanılmamıştır. Dolayısıyla, bu çalışmanın sonuçları konunun daha iyi anlaşılmasına katkıda bulunacaktır.

$\mathrm{Bu}$ çalışmanın bulguları, mobbingin lisans öğrencilerinin tükenmişlik düzeyleri üzerinde anlamlı bir etkisi $(\beta=, 350 ; p<0,01)$ olduğunu göstermektedir. Bununla birlikte, öğrencilerin tükenmişliğinde hem akademik mobbing $(\beta=, 200 ; p<0,01)$ hem de akademik olmayan mobbingin $(\beta=, 358 ; p<0,01)$ etkili olduğu da görülmüştür. Burada akademik olmayan mobbingin öğrenci tükenmişliği üzerinde daha fazla etkili olduğu söylenebilir. Sonuç olarak bu çalışmada ele alınan üç hipotez de kabul edilmiştir. Goodboy ve diğerleri (2015) tarafından lisansüstü öğrenciler üzerinde yapılan bir araştırmada, mobbing ile tükenmişlik arasında pozitif ilişki bulunmuştur. Dolayısıyla her iki çalışmadaki bulgular benzerlik göstermektedir.

Mobbinge maruz kalan bir öğrencide olumsuz psikolojik, zihinsel ve fiziksel tükenmişlik belirtilerinin görüleceği açıktır (Notelaers vd., 2006). Bu noktada, iş yükü-kontrol destek modeli (Karasek, 1979; Van Der Doef ve Maes, 1999) mobbingin tükenmişliğe olan etkisinin açıklanmasında kullanılabilir. Buna göre, mobbinge maruz kalan bir öğrenci, iş yükünü (sınıf içi etkinlikler, ev ödevleri, sınavlar vb.) yerine getirmenin -fiziksel ve zihinsel sağlığı üzerindeki olumsuz etkileri nedeniyle- zorluğunu yaşayacak ve bunları kontrol etmede başarılı olamayacaktır. Ayrıca, mağdurun diğer öğretim elemanları ve arkadaşlarından gerekli bilgi, psikolojik ve sosyal desteği alamaması durumunda, mobbingin olumsuz etkileri daha güçlü olacaktır. Mobbing sonucu yaşanabilecek yüksek tükenmişlik düzeyleri, öğrencilerin akademik başarısızlığına yol açabilecektir. Bu noktada, yapılmış bazı araştırmalar sosyal desteğin önemini vurgulamaktadır. Bu araştırmalar okul yönetimi ve öğretmenler tarafindan sosyal destek sağlanması durumunda öğrenci stresi (Park vd., 2015) ve tükenmişlik düzeyinin (Kim vd., 2017) azalacağını ileri sürmektedirler.

$\mathrm{Bu}$ çalışmanın sonuçlarına göre, mobbing ve tükenmişlik konularının okul yönetimleri tarafından dikkate alınması gerektĭgi açıktır. Mobbing mağduriyeti ve tükenmişlik tek bir öğrencide görülse dahi önemlidir. Tükenmişliğin; verimliliği ve performansı düşürmesi, okula ve derslere karşı negatif tutuma yol açması, insan ilişkilerini bozması, gerilim ve çaresizlik hissi yaratması (Yıldız, 2015) gibi olumsuz durumlara sebep olabileceği göz önüne alındığında, okul yönetimlerinin olası mobbing davranışlarını önlemeye yönelik bir takım tedbirler alması gerektiği söylenebilir. Örneğin, farkındalık eğitimleri düzenlenerek bu tür davranışların hiçbir düzeyde hoş karşılanmayacağı yönünde güçlü mesajlar verilebilir. Potansiyel mobbing davranışlarını en aza indirmek için okul yönetimi tarafından güçlü sosyal ağlar ve mekanizmalar geliştirilebilir. Mobbinge maruz kalma nedeniyle tükenme belirtileri (depresyon, başarıda düşüş hissi) görülen öğrencilere yönelik sosyal destek sağlanması faydalı olabilir. Sonuç olarak, mobbing davranışlarını azaltma çabaları tükenmişlik yaşama olasılığını ortadan kaldıracak ve bu çabalar öğrencilerin bireysel performanslarının artmasına katkıda bulunacaktır.

$\mathrm{Bu}$ çalışma yükseköğrenimde bulunan lisans öğrencileri ile sınırlıdır. Gerek örneklem miktarından, gerekse lisans öğrencilerine odaklanılmasından dolayı bu çalışmanın sonuçları tüm eğitim düzeylerine genellenemez. Elde edilen sonuçların genel olup olmadığını ve farklı 
Yıldız, S.M. (2020). Mobbing davranışlarının öğrenci tükenmişliğine etkisi: Spor Bilimleri Fakültesi lisans öğrencileri üzerinde ampirik bir inceleme. Spor Bilimleri Araştırmaları Dergisi, 5(1), 1-14.

örneklemlerde tutarlı olup olmadığını belirleyebilmek için tüm eğitim düzeylerinde daha fazla araştırma yapılmasına ihtiyaç duyulmaktadır. Dolayısıyla, araştırmacılara, NDÖ-Ö’yü kullanarak lise, lisans, ön lisans, yüksek lisans veya doktora düzeylerinde benzer çalışma yapmaları önerisi verilebilir.

Yayın Etiği: Mevcut çalışmanın yazım sürecinde "Yükseköğretim Kurumları Bilimsel Araştırma ve Yayın Etiği Yönergesi” kapsamında bilimsel, etik ve alıntı kurallarına uyulmuş olup; toplanan veriler üzerinde herhangi bir tahrifat yapılmamış ve bu çalışma herhangi başka bir akademik yayın ortamına değerlendirme için gönderilmemiştir.

\section{KAYNAKLAR}

Alex-Hart, B.A., Okagua, J. and Opara, P. (2015). Prevalence of bullying in secondary schools in Port Harcourt. Int J Adolesc Med Health, 27(4), 391-396. DOI: https://doi.org/10.1515/ijamh-2014-0038.

Brislin, R.W. (1970). Back-translation for cross-cultural research. Journal of Cross-cultural Psychology, 1(3), 187-216. DOI: https://doi.org/10.1177/135910457000100301.

Browne, M.W. and Cudeck, R. (1993). Alternative ways of assessing model fit. In: K. A. Bollen \& J.S. Long (Eds) Testing structural equation models. Newbury Park: Sage.

Byrne, B.M. (2001). Structural equation modeling with AMOS - Basic concepts, applications, and programming. Mahwah, NJ: Lawrence Erlbaum Associates Inc., Publishers.

Einarsen, S., Hoel, H. and Notelaers, G. (2009). Measuring exposure to bullying and harassment at work: Validity, factor structure and psychometric properties of the Negative Acts Questionnaire-Revised. Work \& Stress, 23(1), 24-44. DOI: https://doi.org/10.1080/02678370902815673.

Furrer, C.J, Skinner, E.A. and Pitzer, J.R. (2014). The influence of teacher and peer relationships on students' classroom engagement and everyday motivational resilience. National Society for the Study of Education, $113(1), 101-123$.

Giovazoalias, T. and Malikiosi-Loizos, M. (2015). Bullying at Greak universities: Cross-national perspectives. In H. Cowie, C.A. Myers (Eds.), Bullying among university students (pp. 110-126). London: Routledge.

Goodboy, A., Martin, M. and Johnson, Z. (2015). The relationships between workplace bullying by graduate faculty with graduate students' burnout and organizational citizenship behaviors. Communication Research Reports, 32(3), 272-280. DOI: https://doi.org/10.1080/08824096.2015.1052904.

Heinemann, P. (1972). Mobbning - Gruppvåld bland barn och vuxna (Mobbing - Group Violence by Children and Adults). Stockholm: Natur and Kultur.

Hoover, J.H., Oliver, R. and Hazler, R.J. (1992). Bullying: Perceptions of adolescent victims in the midwestern USA. School Psychology International, 13(1), 5-16. DOI: https://doi.org/10.1177/0143034392131001.

Jacobs, S.R. and Dodd, D. (2003). Student burnout as a function of personality, social support, and workload. Journal of College Student Development, 44(3), 291-303. DOI: https://doi.org/10.1353/csd.2003.0028.

Karasek, R.A. (1979). Job demands, job decision latitude, and mental strain: Implications for job redesign. Administrative Science Quarterly, 24(2), 285-308. DOI: https://doi.org/10.2307/2392498.

Karık, T. ve Yıldız, S.M. (2015). Mobbing davranışlarının kadın basketbolcuların tükenmişliği üzerine etkisi. Uluslararası Insan Bilimleri Dergisi, 12(2), 430-442. DOI: https://doi.org/10.14687/ijhs.v12i2.3349.

Kim, B., Jee, S., Lee, J., An, S. and Lee, S.M. (2017). Relationships between social support and student burnout: A meta-analytic approach. Stres \& Health, 34(1), 127-134. DOI: https://doi.org/10.1002/smi.2771. 
Yıldız, S.M. (2020). Mobbing davranışlarının öğrenci tükenmişliğine etkisi: Spor Bilimleri Fakültesi lisans öğrencileri üzerinde ampirik bir inceleme. Spor Bilimleri Araştırmaları Dergisi, 5(1), 1-14.

Leymann, H. (1996). The content and development of mobbing at work. European Journal of Work and Organizational Psychology, 5(2), 165-184. DOI: https://doi.org/10.1080/13594329608414853.

Lorenz, K. (1963). On Aggression. San Diego, CA: Harcourt Brace.

Maslach, C. (2003). Job burnout: New directions in research and intervention. Current Directions in Psychological Science, 12(5), 189-192. DOI: https://doi.org/10.1111/1467-8721.01258.

Maslach, C. and Leiter, M.P. (2008). Early predictors of job burnout and engagement. Journal of Applied Psychology, 93(3), 498-512. DOI: https://doi.org/10.1037/0021-9010.93.3.498.

McCarthy, M.E., Pretty, G.M. and Catano, V. (1990). Psychological sense of community and student burnout. Journal of College Student Development, 31(3), 211-216.

Metzger, A.M., Petit, A. and Sieber, S. (2015). Mentoring as a way to change a culture of academic bullying and mobbing in the humanities. Higher Education for the Future,2(2), 139-150. DOI: https://doi.org/10.1177/2347631115584119.

Neumann, Y., Finaly-Neumann, E. and Reichel, A. (1990). Determinants and consequences of students' burnout in universities. The Journal of Higher Education, 61(1), 20-31. DOI: https://doi.org/10.1080/00221546.1990.11775089.

Notelaers, G., Einarsen, S., De Witte, H. and Vermunt, J.K. (2006). Measuring exposure to bullying at work: The validity and advantages of the latent class cluster approach. Work \& Stress, 20(4), 289-302. DOI: https://doi.org/10.1080/02678370601071594.

Öntürk, Y. (2018). Spor ortamında mobbing. Ankara: Gece Kitaplığı Yayınevi.

Park, K.H., Kim, D.H, Kim, S.K., Yi, Y.H., Jeong, J.H., Chae, J., Hwang, J. and Roh, H.R. (2015). The relationships between empathy, stress and social support among medical students. International Journal of Medical Education, 6, 103-108. DOI: https://doi.org/10.5116/ijme.55e6.0d44.

Pienaar, J. and Sieberhagen, C. (2005). Burnout and engagement of student leaders in a higher education institution. South African Journal of Higher Education, 19(1), 155-166.

Rahmati, Z. (2015). The study of academic burnout in students with high and low level of self-efficacy. Procedia-Social and Behavioral $\quad$ Sciences, $171(16), \quad$ 49-55. DOI: https://doi.org/10.1016/j.sbspro.2015.01.087.

Salmela-Aro, K., Savolainen, H. and Holopainen, L. (2009). Depressive symptoms and school burnout during adolescence: Evidence from two cross-lagged longitudinal studies. J Youth Adolescence, 38(10), 13161327. DOI: https://doi.org/10.1007/s10964-008-9334-3.

Schaufeli, W.B., Martínez, I.M., Pinto, A.M., Salanova, M. and Bakker, A.B. (2002). Burnout and engagement in university students: A cross-national study. Journal of Cross-Cultural Psychology, 33(5), 464-481. DOI: https://doi.org/10.1177/0022022102033005003.

Schaufeli, W.B. and Taris, T.W. (2005). The conceptualization and measurement of burnout: Common ground and worlds apart. Work \& Stress, 19(3), 256-262. DOI: https://doi.org/10.1080/02678370500385913.

Taştan, N. ve Gökler, R. (2017). Öğrenci görüşlerine göre siber-zorbalık ve okul tükenmişliği arasındaki ilişki. Uluslararası Sosyal Araştırmalar Dergisi, $10(54), \quad 771-777 . \quad$ DOI: http://dx.doi.org/10.17719/jisr.20175434644.

Thomas, C.H. and Lankau, M.J. (2009). Preventing burnout: The effects of LMX and mentoring on socialization, role stress, and burnout. Human Resource Management, 48(3), 417-432. DOI: https://doi.org/10.1002/hrm.20288.

Tinaz, P. (2006). İşyerinde psikolojik taciz (mobbing). Çalışma ve Toplum, 4(11), 13-28.

Vandekerckhove, W. and Commers, M.S.R. (2003). Downward workplace mobbing: A sign of the times? Journal of Business Ethics, 45(1-2), 41-50. DOI: https://doi.org/10.1023/A:1024168311652. 
Yıldız, S.M. (2020). Mobbing davranışlarının öğrenci tükenmişliğine etkisi: Spor Bilimleri Fakültesi lisans öğrencileri üzerinde ampirik bir inceleme. Spor Bilimleri Araştırmaları Dergisi, 5(1), 1-14.

Varhama, L.M. and Björkqvist, K. (2004). Conflicts, workplace bullying and burnout problems among municipal employees. Psychological Reports, $1116-1124$. DOI: https://doi.org/10.2466/pr0.94.3c.1116-1124.

Vveinhardt, J., Fominiene, V.B. and Andriukaitiene, R. (2019). Encounter with bullying in sport and its consequences for youth: Amateur athletes' approach. International Journal of Environmental Research and Public Health, 16(23), 4685. DOI: https://doi.org/10.3390/ijerph16234685.

Wolke, D., Woods, S., Bloomfield, L. and Karstadt, L. (2001). Bullying involvement in primary school and common health problems. Arch Dis Child, 85(3), 197-201. DOI: https://doi.org/10.1136/adc.85.3.197.

Yamada, S., Cappadocia, M.C. and Pepler, D. (2014). Workplace bullying in Canadian graduate psychology programs: Student perspectives of student-supervisor relationships. Training and Education in Professional Psychology, 8(1), 58-67. DOI: https://doi.org/10.1037/tep0000015.

Yang, H-J. (2004). Factors affecting student burnout and academic achievement in multiple enrollment programs in Taiwan's technical-vocational colleges. International Journal of Educational Development, 24(3), 283-301. DOI: https://doi.org/10.1016/j.ijedudev.2003.12.001.

Yıldız, K. ve Dirik, D. (2019). Algılanan sosyal destek ve stresle başa çıkma tarzları arasındaki ilişkide algılanan öz yeterliliğin rolü. SPORMETRE Beden Eğitimi ve Spor Bilimleri Dergisi, 17(2), 132-144. DOI: https://doi.org/10.33689/spormetre.500792.

Yıldız S.M. ve Tüfekçioğlu, E. (2008). Beden eğitimi ve spor yüksekokullarında eğitim destekleri, kariyer gelişim olanakları ve eğitim sonrasında istihdam durumunun öğretim elemanları ve öğrencilerin görüşlerine göre karşılaştırmalı olarak incelenmesi. Niğde Üniversitesi Beden Ĕ̆itimi ve Spor Bilimleri Dergisi, 2(2), 89-97.

Yıldız, S.M. (2015). Lider-üye etkileşimi, işyerinde mobbing ve mesleki tükenmişlik ilişkisi. Ankara: Detay Yayınevi.

Yıldız, S.M. (2016). İşyerinde mobbing davranışlarının spor ve fiziksel etkinlik işletmeleri çalışanlarının örgütsel vatandaşlık davranışına etkisi. Dokuz Eylül Üniversitesi Sosyal Bilimler Enstitüsü Dergisi, 18(1), 165-180. DOI: https://doi.org/10.16953/deusbed.80977.

Yıldız, S.M. (2017). Örgütsel davranış seçme konular. Ankara: Detay Yayınevi. 
Yıldız, S.M. (2020). Mobbing davranışlarının öğrenci tükenmişliğine etkisi: Spor Bilimleri Fakültesi lisans öğrencileri üzerinde ampirik bir inceleme. Spor Bilimleri Araştırmaları Dergisi, 5(1), 1-14.

\section{EK 1 - Negatif Davranışlar Ölçeği-Öğrenci}

\begin{tabular}{|l|l|l|l|}
\hline & & \\
& & \\
\end{tabular}

\section{APPENDIX - Negative Acts Questionnaire-Student}

\begin{tabular}{|l|l|l|l|l|l|l|l|l|l|l|l|l|}
\hline & \\
& & \\
\hline
\end{tabular}

Bu eser Creative Commons Atıf-GayriTicari 4.0 Uluslararası Lisansı ile lisanslanmıştır. 